\title{
The Social Media Release as a public relations tool: Intentions to use among B2B bloggers
}

\author{
Peter Steyn ${ }^{\mathrm{a}, *}$, Esmail Salehi-Sangari ${ }^{\mathrm{b}}$, Leyland Pitt $^{\mathrm{c}}$, Michael Parent $^{\mathrm{c}}$, Pierre Berthon ${ }^{\mathrm{d}}$ \\ a Division of Industrial Marketing, e-Commerce and Logistics, Luleå University of Technology, Luleå, Sweden \\ b Department of Industrial Economic \& Management (INDEK), Royal Institute of Technology, Stockholm, Sweden \\ c Segal Graduate School of Business, Simon Fraser University, Vancouver, Canada \\ ${ }^{\mathrm{d}}$ Bentley University, Waltham, MA, USA
}

\section{A R T I C L E I N F O}

\section{Article history:}

Received 27 May 2009

Received in revised form 11 August 2009

Accepted 30 September 2009

\section{Keywords:}

Bloggers

Social Media Release

Public relations

Technology Acceptance Model

\begin{abstract}
A B S T R A C T
The Social Media Release (SMR) is emerging as a potentially powerful public relations tool in a world of social network media, particularly when targeted at influential bloggers. The research described here studies the factors that influence bloggers to use SMRs, using the Technology Acceptance Model as a theoretical framework, concentrating specifically on their perceptions of usefulness and ease of use.
\end{abstract}

(c) 2009 Elsevier Inc. All rights reserved.

In the research described in this note, we examine a relatively new public relations (PR) device, the Social Media Release (SMR), and its effects on bloggers. Specifically, we seek to determine what factors will affect their decisions to use SMRs or components of these in the future. We proceed by examining SMRs, defining and describing them, and explore a theoretical framework that permits an explanation of the future uptake of SMRs by bloggers in a business-to-business (B2B) setting. Then, we present the results of a study of whether and why B2B bloggers would use SMRs or elements of them.

\section{The Social Media Release}

The Social Media Release (SMR) is best conceived of as a blend of the traditional press release, and digital social media (e.g. http://www.socialmediarelease.org/). The SMR has evolved as a response to the increase in interactivity permitted by social media and is best conceived of as a digital press release that includes the additional elements a reporter or consumer would want to see before they create their own content to broadcast or transmit further.

Like many offerings of the digital age, the SMR blurs the lines between content and technology. Whether it eventually gets used and becomes an established standard within an industry or a market still depends on whether its users find it easy to use and useful. Whether or not the SMR becomes an accepted standard within the PR community, and among the bloggers that surround it, will depend on the extent to which it is accepted as a technology.

\footnotetext{
* Corresponding author.

E-mail address: petersteyn@gmail.com(P. Steyn).
} 


\section{The Technology Acceptance Model}

Researchers in the field of management information systems (Davis, 1989; Davis, Bagozzi, \& Warshaw, 1989) developed the Technology Acceptance Model (TAM) in order to enhance our understanding how users come to accept and use a technology. TAM proposes that when users are presented with a new technology, two factors, perceived usefulness and perceived ease of use influence whether they will use it.

Our thinking regarding the use and intentions to use of SMR's by bloggers was that, as a relatively new technology in PR, their current use by bloggers would have been affected firstly by their perceptions of its effectiveness (a surrogate for usefulness), and secondly by subjective norms, in this case their perceptions of the extent of its current use by companies. Therefore:

$\mathrm{H}_{1}$ : Bloggers' perceptions of the effectiveness of SMR are positively related to their use of SMR elements;

$\mathrm{H}_{2}$ : Bloggers' perceptions of the current use of SMR by companies are positively related to their use of SMR elements;

$\mathrm{H}_{3}$ : Bloggers' current use of SMR or elements thereof will be positively related to their future intentions to use SMR or elements thereof.

\section{Bloggers and SMR: an international survey}

Organizations have found that in many instances their best avenues to get their messages to target audiences in a credible way are no longer through traditional media, but by way of blogs and the bloggers who construct them. Therefore, we surveyed by means of email a sample of 800 bloggers identified through the database of Text100, a global PR consultancy firm serving the technology industry. A total of 332 usable responses were received at the time of cut-off (response rate of $41.5 \%$ ), all of whom were active bloggers who regularly commented on technology products and services in a B2B environment, news and lifestyles; whose opinions were regarded as influential in these fields; and who were targeted as prominent commentators by PR firms and departments. 141 respondents (42.5\%) knew what an SMR was. These respondents were then asked:

1. "How effective do you think SMRs are as a means to keep you updated on corporations?" ( 1 = "not effective at all" through 7 = "very effective"). Mean response: 4.78 .

2. "Compared with a year ago, to what extent are companies using SMRs to communicate with you and other bloggers?" ( 1 = decreased significantly through $5=$ increased significantly). Mean response: 3.79 .

3. "In the past year, how often have you taken elements (video, quotes, pictures, links) from SMRs to use in your own blog postings?" ( 1 = never through $5=$ always $)$. Mean response: 2.77 .

4. "In the next year, how often are you likely to use elements from SMRs for use in your own blog postings?" $(1=$ significantly less often through 5 = significantly more often). Mean response: 3.72 .

The research model and its associated hypotheses were analyzed using the covariance-based structural equation modeling (SEM) technique (Hair, Black, Babin, Anderson, \& Tatham, 2006). The fit of the theory to the data was strongly supported $\left(\chi^{2}=3.74,2 \mathrm{df}, p=.159\right.$, not significant at the $5 \%$ level). All the path coefficients were significant.

The results of the analysis can be summarized as follows: a bloggers' perceptions of the effectiveness of SMRs are positively and significantly related to their use of SMR elements $(.25, t=3.32)$, while at the same time, their perceptions of the current use of SMRs by companies are also positively and significantly related to their use of SMR elements $(.19, t=2.40) . \mathrm{H}_{1}$ and $\mathrm{H}_{2}$ are thus accepted. In addition, a blogger's current use of SMRs or elements thereof significantly influenced their intended future use of the technology $(.45, t$

6.03). $\mathrm{H}_{3}$ is therefore also accepted.

\section{Conclusion: limitations, implications for PR practitioners and avenues for future research}

The SMR is a relatively new technology in PR, and it may be that we conducted this research too early: a majority of the intended respondents (57.5\%) had not yet been exposed to it. A follow-up study in the near future can determine whether awareness has increased and whether this has an effect on use and usage intentions. Only single item scales were used to measure the constructs in the research model, where multi-item scales would obviously have been better. Our approach approximates, rather than replicates TAM studies grounded in the theories of planned behavior and reasoned action.

Implications for PR practitioners are that bloggers are influenced in their intentions to use SMRs in the future not only by their current use of the device, but also by their perceptions of their effectiveness and the use of SMRs by others. PR practitioners might find it worthwhile to identify ways of making bloggers aware of SMRs. PR practitioners should educate bloggers concerning the effectiveness of SMRs and also about which organizations are using them and how well they are working. There may be business opportunities for those PR firms that are able to provide education and training on the use of SMRs, their construction and their deployment. 
This study suggests a number of avenues for future research by PR scholars. First, it would be worthwhile to ascertain further what differences exist between those who are aware of a new technology such as SMRs, and those that are not. Second, a future study of the intentions to use technologies by bloggers and other PR publics would benefit from using multi-item scales to measure constructs such as perceived usefulness, ease of use and subjective norms. Third, other constructs could be built into the kinds of path analysis utilized in this study, so that the current concepts could be further understood and linked to other behaviors.

\section{Acknowledgement}

The authors gratefully acknowledge the assistance of Text100 Public Relations, Asia Pacific, who identified the bloggers, managed the outreach and allowed the data for further analysis.

\section{References}

Davis, F. D. (1989). Perceived usefulness, perceived ease of use, and user acceptance of information technology. MIS Quarterly, 13(3), 319-340.

Davis, F. D., Bagozzi, R. P., \& Warshaw, P. R. (1989). User acceptance of computer technology: A comparison of two theoretical models. Management Science, 35, 982-1003.

Hair, J. F., Black, W. C., Babin, B. J., Anderson, R. E., \& Tatham, R. L. (2006). Multivariate data analysis. Englewood Cliff, NJ: Pearson Prentice Hall. 